\title{
Feline Mammary Carcinoma
}

National Cancer Institute

\section{Source}

National Cancer Institute. Feline Mammary Carcinoma. NCI Thesaurus. Code C132274.

Mammary carcinoma occurring in a cat. 